\title{
The Controversy over the AMS Publishing Original Investigations
}

\section{Steve Batterson}

AUTHOR'S NOTE TO THE READER. This article is excerpted, with minor revisions, from the fifth chapter of my book American Mathematics 1890-1913 Catching up to Europe. The chapter is about the early years of the AMS. The Society was founded in 1888 as the New York Mathematical Society out of an initiative from Columbia graduate student Thomas Fiske. A few years later it became a national organization with its present name. Two disputes soon arose that threatened to fracture the AMS. The first dispute concerned the establishment of a Chicago regional section to accommodate Midwestern members of the eastern-dominated organization. The second controversy grew out of questions related to appropriate publication venues for original research by American mathematicians. This excerpt concerns the second of these disagreements. Additional archival references are available in [3].

The publication of mathematical research is presently at the core of the AMS mission. This role for the Society seems so natural that the drama and contention behind the founding of its first research journal, the Transactions, is surprising. In 1898, however, the most prominent American mathematicians in the organization stood in opposition to the AMS sponsoring a research journal. The dispute began when some AMS members expressed dissatisfaction with the existing opportunities for publishing their research in the United States. The issue centered on whether the AMS should step in to address the problem. This time the division fell along generational, rather than geographic, lines.

Since 1884, when astronomer Ormond Stone started the Annals of Mathematics, ${ }^{1}$ two American journals had existed for the dissemination of mathematical research. The American Journal of Mathematics (AJM) continued to publish scholarship at a high level. The Annals, with a mis-

Steve Batterson is Professor Emeritus of Mathematics and Computer Science at Emory University. His email address is sb@emory . edu.

${ }^{1}$ On Stone and the Annals, see [4].

For permission to reprint this article, please contact: reprint -permission@ams.org.

DOI: https://dx.doi.org/10.1090/noti 1873 sion to serve a wider audience, printed papers of a more intermediate quality.

For Stone the Annals was a labor of love. He self-financed the journal after coming to the University of Virginia to direct its observatory. Stone often published articles for which, though the originality of the results was marginal, the presentation made mathematical topics more accessible. In the 1890s the journal continued to fill this niche as it added stronger material from the rapidly developing American mathematical community. At the same time, resentment was building among young Americans over the editorial management of the AJM. An analysis of their grievances requires some background on the AJM and its administration at Johns Hopkins University.

Prior to the founding of the AJM in 1878, American mathematicians had no domestic periodical for conveying important discoveries to an international audience. Since major results were then exceedingly rare in the United States, the deficiency had infrequent effect. Nevertheless, Benjamin Peirce's 1870 paper, on linear associative algebras, and G. W. Hill's 1877 paper, with the differential equation that now carries his name, were necessarily printed privately. 


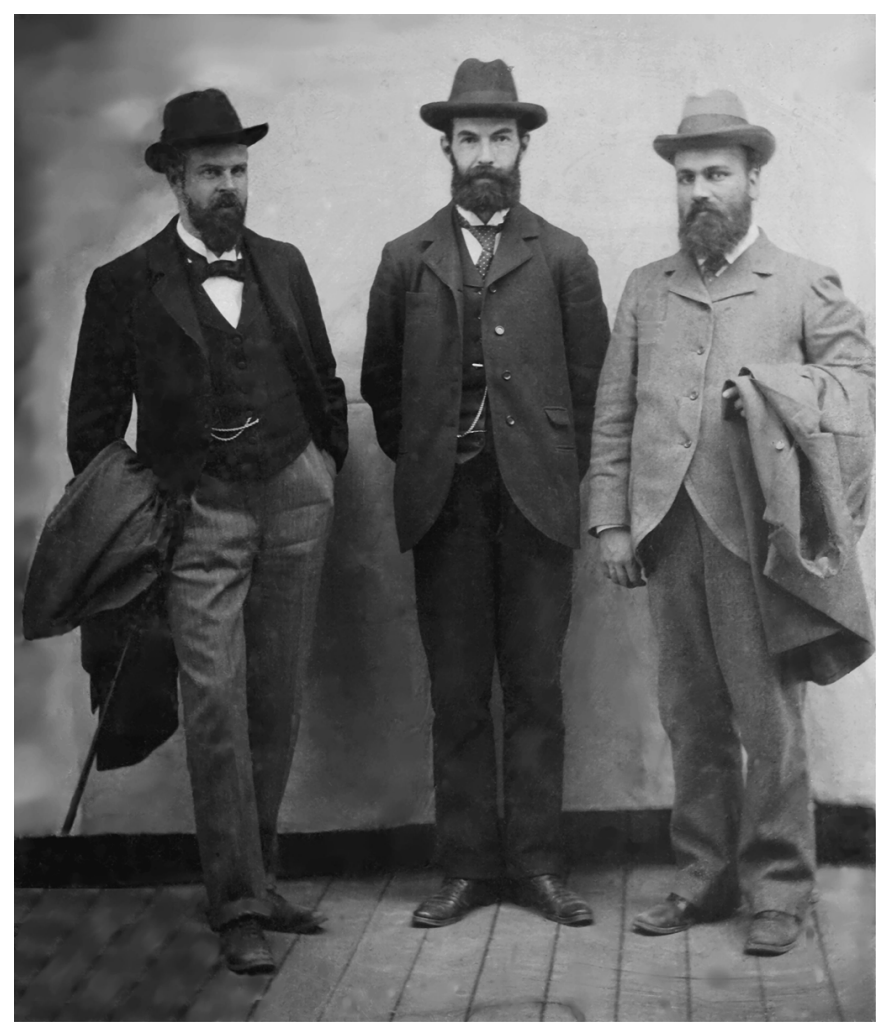

James Pierpont, William Fogg Osgood, and Maxime Bôcher (1899), from the 1860s-born generation that led the AMS into the publication of original research. They also were three of the first four AMS Colloquium lecturers.

Johns Hopkins President Daniel Coit Gilman² recognized the need for an American mathematics journal to support scholarship in the country. He pushed his mathematics professor J. J. Sylvester to begin a mathematics journal attached to Hopkins. Sylvester at first demurred, pointing to the dearth of material originating in the United States.

With the assurance of financial support from the University and administrative assistance from his junior colleague William Story, Sylvester finally agreed to undertake the journal project. The venture was highly speculative, depending as it did on an increase in American research. To fill its early issues, and maintain the journal's distinction, Sylvester solicited papers from prominent European associates. Along with Hill's seminal work on the lunar theory and articles by Sylvester, Simon Newcomb, and Henry Rowland, the first issues included papers by the British mathematicians Arthur Cayley and W. K. Clifford. The work of Sylvester's students was soon supplementing the articles by Hopkins faculty, other Americans, and European contributors. The international combination was an overwhelming success,

\footnotetext{
${ }^{2}$ The remainder of this paragraph and the following one are drawn largely from [5], where more is available on the AJM.
}

bringing credit to Johns Hopkins. Over Sylvester's six-year tenure the authorship breakdown was 25\% European, 45\% Hopkins, and 30\% other American.

During the 1880s the editorial roles of the departing Sylvester and Story were assumed by Newcomb and Sylvester's former student, Thomas Craig. Over time Craig's duties expanded. In 1894 he was promoted from associate editor to editor, with Newcomb taking on advisory status. The practice of soliciting papers from Europeans continued. Meanwhile, since the departure of Sylvester, Hopkins was a declining source of mathematical research.

Talented young American faculty recently returned from study in Europe, such as Maxime Bôcher (Harvard), W. F. Osgood (Harvard), E. H. Moore (Chicago), Henry Seely White (Northwestern), and James Pierpont (Yale), naturally looked to place their papers in the still prestigious AJM. They had mixed results. Bôcher recorded the following comment about an article he published in the 1892 Annals: "A similar paper was sent to Craig for the American Journal in October 1891 and ignored by him." ${ }^{3}$ Whether Craig was disrespecting Bôcher or had a reasonable explanation, the AJM did come to recognize the contributions by the new generation, to some extent. Bôcher, Osgood, Moore, and White each had one paper, and Pierpont had two in the

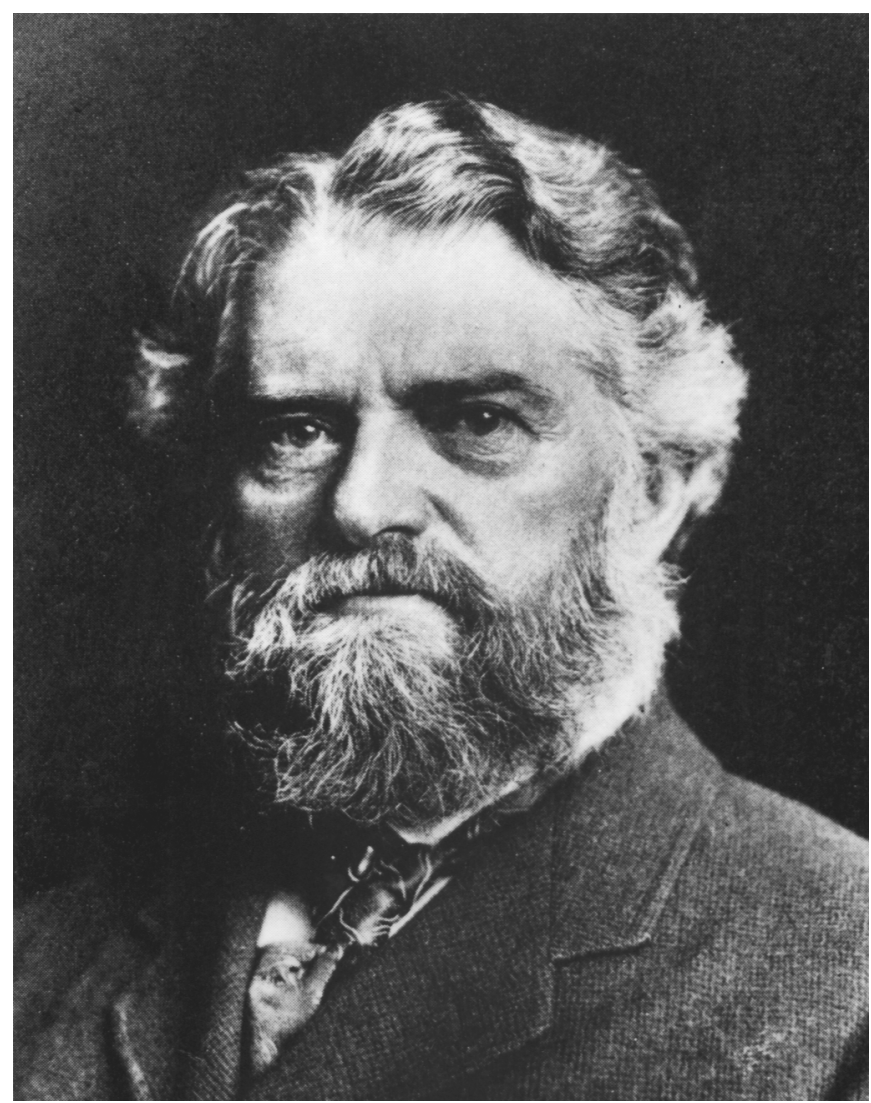

Simon Newcomb, AMS President, 1897-1898.

${ }^{3}$ From the notebook, with annotations on his publications, among the Papers of Maxime Bôcher. HUG 1224.5. Harvard University Archives. 
volumes over the years 1895-1897. During this three-year period the percentage of Hopkins papers dropped, from the Sylvester days, to $19 \%$ as the other American institutions' share rose to $40 \%$. European contributions, at $40 \%$, had also increased.

With contact facilitated by the meetings of the AMS, the young cohort became aware of worthy domestic results that were not appearing in the AJM. They resented the AJM practice of committing in advance to publish papers of Europeans, leaving inadequate space for Americans. Moreover, they shared stories of sloppy editing and poor refereeing for which they blamed Craig. By 1898 the notion had arisen of the AMS sponsoring a research journal.

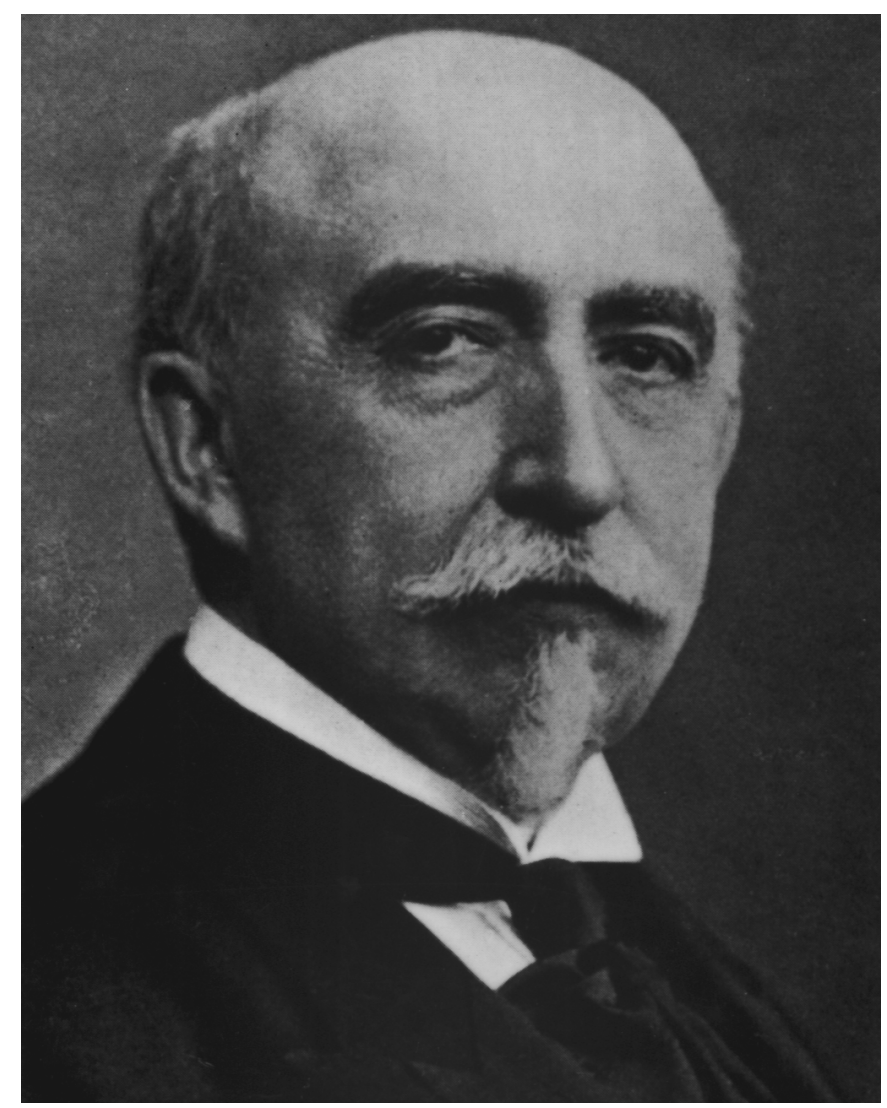

John Emory McClintock, AMS President, 1891-1894.

It was not the first time that members of the Society had discussed the possibility of publishing original investigation. In 1891, when Emory McClintock was the Society president, the New York Mathematical Society had rejected this course for its Bulletin. McClintock and his presidential successor, G. W. Hill, were from an older generation. Their professional lives were markedly changed by the creation of the AJM. McClintock and Hill felt it impudent for the Society to infringe on what they regarded as Johns Hopkins' franchise. A committee, which included McClintock and Fiske, decided on a policy for the Bulletin to carry primarily articles of a "critical and historical nature."
For mathematicians in their thirties such as Bôcher, Moore, Pierpont, White, and Osgood, the AJM had existed throughout their careers, operating, in their opinion, with a European bias. The developing state of American mathematics in 1898 simply called for another journal. Bulletin editor Thomas Fiske appreciated the delicacy of the situation. Although he was from the younger generation and shared their views, he, alone of them, had participated in the discussions earlier in the decade. Any proposal would involve the current AMS president, Simon Newcomb, who would be especially sensitive to the treatment of the AJM with which he had been associated from its conception.

Fiske sought a course to accommodate all parties. Journals were financial burdens for universities. The University of Virginia had taken over support of the Annals from Stone, only recently finding itself unable to sustain the funding. The AJM was a continuing expense for Johns Hopkins. Perhaps Hopkins would relinquish control to the AMS if the Society assumed financial responsibility while perpetuating the AJM's Baltimore heritage. On March 29, 1898 Fiske wrote Newcomb:

It has on several occasions been suggested that the American Mathematical Society undertake the publication of a journal of original investigation. The supply of original material suitable for publication has been increasing rapidly in the past two years, and it seems desirable either that the American Journal should be enlarged or that a new journal should be established. How does the following proposition impress you?

That, the American Journal be transferred to the American Mathematical Society, it being agreed that the title-page and cover shall always bear in a conspicuous position the inscription

"Founded by the Johns Hopkins University" 4

Although turning over the AJM proved to be a nonstarter with Hopkins, Newcomb seemed open to some sort of cooperative relationship with the AMS. At the 1898 AMS Summer Meeting a special committee was constituted with the broad charge "to consider the question of securing improved facilities for the publication of original mathematical articles in this country." ${ }^{15}$ The committee members were Bôcher, Moore, Newcomb, and Pierpont, with Fiske

\footnotetext{
${ }^{4}$ From the Simon Newcomb Papers. Manuscript Division, Library of Congress.

${ }^{5}$ P. 2 in the October 1898 Bulletin.
} 
as chair. Its first efforts were in pursuit of an arrangement with Hopkins for joint custody of the AJM. ${ }^{6}$

Fiske found himself functioning as an intermediary, between Bôcher, Moore, and Pierpont on one side and Newcomb on the other. The agenda of the four younger men was simple. The AMS needed to gain editorial control of the AJM. Over the short run they would be satisfied with substantially reducing the authority of Craig while publishing more papers by Americans.

Guided by a report of the special committee and reaction from the AMS Council, Fiske and Moore drew up a formal proposal. Its business aspects were straightforward. The number of AJM issues per year would increase from four to six, with the AMS footing the added expense. Seemingly more controversial was their plan for editorial reorganization. Rather than a single editor selected by Hopkins, "the Journal shall have a board of seven editors, of whom several (two) shall be selected by Johns Hopkins University, and the others (five) by the Council of the American Mathematical Society." The board was to elect, "from among themselves," an editor in chief under the stipulation that Newcomb would serve as the first editor in chief. ${ }^{7}$

The parenthetical entries in the proposal suggest that Fiske and Moore anticipated some negotiation over the number of editors to be selected by the two entities. Ironically, the integers two and five were rare aspects of the proposal over which there is no record of disagreement. The negotiations between Fiske and Newcomb were tense, eliciting frustration on the part of the otherwise diplomatic Fiske. From the outset they haggled over the AMS subvention. To offset the cost of the additional issues Newcomb proposed the AMS contribute $\$ 500$ per year and assume responsibility for 100 new subscribers. A skeptical Fiske began asking for, and not receiving, specifics on the current AJM operating expenses.

The biggest dispute was over the powers and titles, rather than the number, of the Hopkins editors. The nomination of Newcomb as the first editor in chief, suggested by Moore, was a short-term gesture intended to ease Craig out of authority and acknowledge Newcomb's eminence. The younger committee members were adamant that Newcomb's successors be elected from, and by, the entire board. Newcomb maintained that fundamental editorial responsibilities could only be performed by someone on the ground in Baltimore where the journal was printed. To handle these duties required an editor in chief and an associate editor in chief, both from Johns Hopkins. Under

\footnotetext{
${ }^{6}$ The following discussion of the committee's work is drawn from two archival collections and from p. 56-61 in [2]. The archival collections are the Henry Seely White Correspondence in the Columbia University Rare Book and Manuscript Library and the Simon Newcomb Papers in the Manuscript Division of the Library of Congress.

${ }^{7}$ The proposal, dated 10/29/1898, is among the Simon Newcomb Papers. It is also printed, without the parentheses, on p. 56 in [2].
}

Newcomb's scheme the AMS designees would carry the title of associate editor.

As the Bulletin was printed in Pennsylvania and edited in New York, Newcomb's reasoning was received with considerable skepticism. Moreover, his counter-proposal was completely unacceptable to the other committee members. Their nightmare scenario was having Craig continue his management function under the title of associate editor in chief, leaving the AMS representatives merely as referees. Bôcher, Moore, Pierpont, and Fiske were unanimous that all board members, other than the editor in chief, have equal standing.

The bottom line was that both sides were determined to hold editorial control of the AJM. Newcomb invited the committee to Hopkins for a discussion with Gilman. Fiske was willing to make the trip himself, but was reluctant to urge his colleagues on the committee to join him. He wrote Newcomb: "Before we can ask our representatives to attend at their own expense a conference to be held in Baltimore, we must assure ourselves that there is some probability of an agreement being reached-I must confess that I am becoming quite doubtful as to whether our negotiations can lead to a mutually satisfactory understanding - "

Other committee members were more pessimistic. Even so, Fiske wanted to make every effort on behalf of the AMS. He wrote to Bôcher, Moore, and Pierpont asking them to accompany him to Baltimore. Only Pierpont agreed to join Fiske for the meeting. At about the same time, Pierpont made arrangements to attend the Chicago section meeting at the end of the year to, among other things, fill in Moore and White on developments.

On Saturday, December 17, 1898, Fiske and Pierpont met with Newcomb and Gilman in Baltimore to discuss a cooperative arrangement between Hopkins and the AMS on the AJM. The following day Pierpont sent this postmortem to White from Washington.

...the Amer Math Soc met its Waterloo. Gilman,
contrary to the notion the Newcomb letters to
Fiske awoke, insisted that the J.H.U. retain ab-
solute control of the journal. Gilman would not
listen to a board of editors appointed by J.H.U.
\& the Amer Math Soc which should guide the
policy of the journal. Fiske tried by diplomatic
word twisting to get Gilman to recede in some
respects. But Gilman would not move an inch.
On the other hand a plan was evolved that the
JHU under leadership of Newcomb should try
in every possible way to meet the wishes of the
Society. Increase number of pages, ask certain
members of the Am M. S. to become advisory
editors \&c \&c. All this shall not cost the Soc a

${ }^{8}$ Simon Newcomb Papers. Letter from Fiske, 11/27/1898. Manuscript Division, Library of Congress. 
cent. Certainly very magnanimous on the part of Gilman. It remains now for the soc. to see if it will accept or shall set out \& form a new journal. ${ }^{9}$

Pierpont was left to ponder what steps Newcomb would take, and whether they would be satisfactory in any way. After some time as a tourist in Washington, Pierpont stopped in Baltimore on his return to New Haven. A meeting with Craig ended any hope of meaningful accommodation. Craig told Pierpont that, without additional funds from the AMS, there was no prospect of enlarging the AJM. The practice of soliciting papers from Europeans would continue.

Upon the failure of the AJM negotiations, contemporary mathematicians might ask why the AMS did not pursue an arrangement to upgrade the Annals. After all, the Annals has been one of the world's most prestigious journals throughout the careers of all living mathematicians. At the end of 1898 , however, the rise in stature of the Annals was a few decades and two venue changes in the future. As strange as it may now be to think of the Annals typecast in the second class, the ordering of the two American journals was taken for granted. Discussion about the Annals concerned

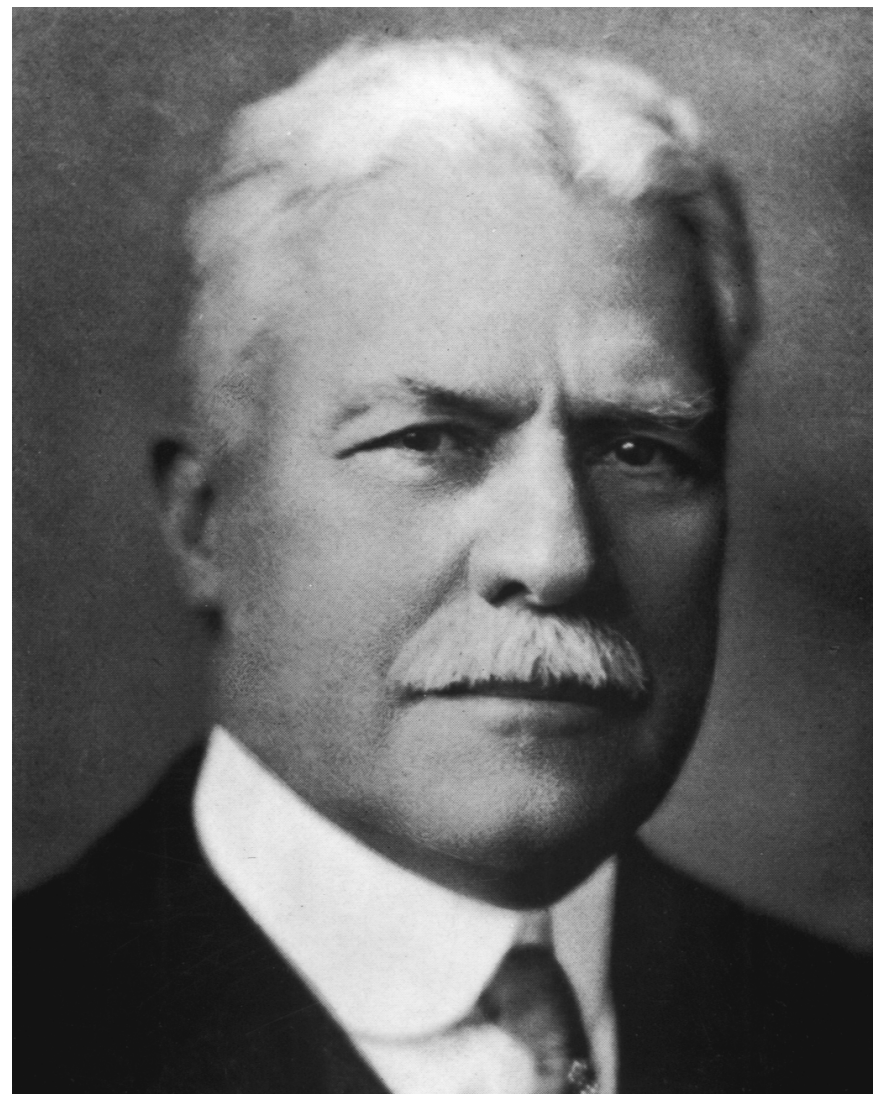

Thomas Scott Fiske, AMS President, 1903-1904.

\footnotetext{
${ }^{9}$ Henry Seely White Correspondence. Letter from Pierpont, 12/18/1898. Columbia Rare Book and Manuscript Library.
}

surviving its financial difficulties, rather than competing with the AJM.

Many of the younger Americans were disheartened. Johns Hopkins stood as the effective arbiter of significant mathematics in the United States. The only alternative course, starting a new AMS journal, faced three formidable obstructions. The first was financial. In 1898 total AMS receipts were $\$ 1831$ and disbursements were \$1614 with $\$ 1363$ going to the Bulletin. While a $\$ 500$ subvention to the AJM seemed doable, launching a journal would necessitate obtaining on the order of $\$ 1500$ in additional annual revenue. Then there was the question of whether sufficient quality research was being produced to fill the pages of the new journal. That the AJM was shunning good material did not imply Americans were writing enough to sustain an entire new periodical. Finally came the political barriers. Former presidents McClintock and Hill and outgoing president Newcomb were firmly against the AMS publishing original research. Overcoming their opposition risked provoking the biggest crisis in the history of the Society.

One week after his unsettling meeting with Craig, Pierpont arrived in Chicago and began talks with Moore and White. As depressing as the Baltimore developments had been, another effect was to focus attention on the feasibility of a new journal. Moore, Pierpont, and White confronted the second barrier directly. They made a careful analysis of the output of mathematical research in the United States. As Fiske later wrote Newcomb: "After much hand calculation and discussion of statistics, they reached a conclusion which surprised them, but which they believed trustworthy. It was that the amount of available good material produced at home, together with the supply the A.J.M. regularly receives from abroad, was more than double the present capacity of the A.J.M." 10

From this point on Pierpont campaigned for the new journal with an evangelical zeal. On his return to Yale, Pierpont stopped in Philadelphia, Princeton, and New York to lay out the case for other Society members. He corresponded with Osgood. The supply issue was resolved. Money and politics remained.

Paralleling Pierpont's lobbying was an effort by Newcomb to placate the AMS by signing up select members, including Fiske and Moore, as associate editors for the AJM. Fiske initially agreed to serve, but continued to communicate with others, such as Moore, who was stalling for time to wait on developments with the AMS journal. In mid-January Moore and Fiske sent Newcomb their regrets. With his response to Fiske, Newcomb portrayed himself as an aggrieved party:

The Mathematical Society desired improved facilities, etc. I suggested that we could get these

\footnotetext{
${ }^{10}$ Simon Newcomb Papers. Postscript in letter from Fiske, 1/26/1899. Manuscript Division, Library of Congress.
} 
facilities by an arrangement with the American Journal of Mathematics. The Society wished the Journal conducted with more sympathy toward our American contributors. They wanted the prospect of more attention to their wishes. They did me the very high honor of making it the condition that I should be Editor-in-Chief. I therefore accepted the rather onerous and responsible duties of this post, much against my inclination, because I wished the end the Society had in view carried out.

The Society wished a body of associate-editors. This also was granted, and after consultation with yourself and others, the desired members were asked to act as my associates. Thus, with a great deal of labor, past and future, I have succeeded, I believe, in getting for the Society everything it could consider really necessary to the end in view. Moreover, this was done without any call on our funds. And now, after I have done all this, the Society runs away from me, as it were, and refuses to furnish the associate-editors, or to have anything to do with the arrangement. ${ }^{11}$

Newcomb had glossed over crucial areas of contention. Fiske prefaced his rebuttal by stipulating that, while others were enthusiastically advocating a new journal, he, himself, remained neutral. He went on to point out the unresolved grievances over the roles of associate editors and Craig, and the two-track handling of European and domestic submissions. In a postscript, Fiske presented the position of Pierpont, Moore, and White, first citing their study and closing with "[o]n the basis of this calculation they demand increased facilities for publication. On the ground that the A.M.J. [sic] cannot provide these facilities without our financial assistance, and that we cannot render such assistance while the J.H.U. maintains its present attitude, they ask for the establishment of a new journal."12

A showdown over the controversial proposal for a new journal was shaping up for the February AMS Council meeting in New York. To clear the air, Fiske scheduled a dinner get-together for interested parties on the prior evening. Pierpont marshalled all the eastern supporters to attend. Newcomb decided to remain at home. He had just handed over the AMS presidency to Robert Woodward, a Columbia mechanics professor. Approaching his $50^{\text {th }}$ birthday, Woodward was born between the two generations involved in the dispute. Newcomb conveyed his views in a letter to McClintock. Fully aware of the arguments on both sides,

\footnotetext{
$\overline{{ }^{11} P .57 \text { in [2] }}$

${ }^{12}$ Simon Newcomb Papers. Letter from Fiske, 1/26/1899. Manuscript Division, Library of Congress.
}

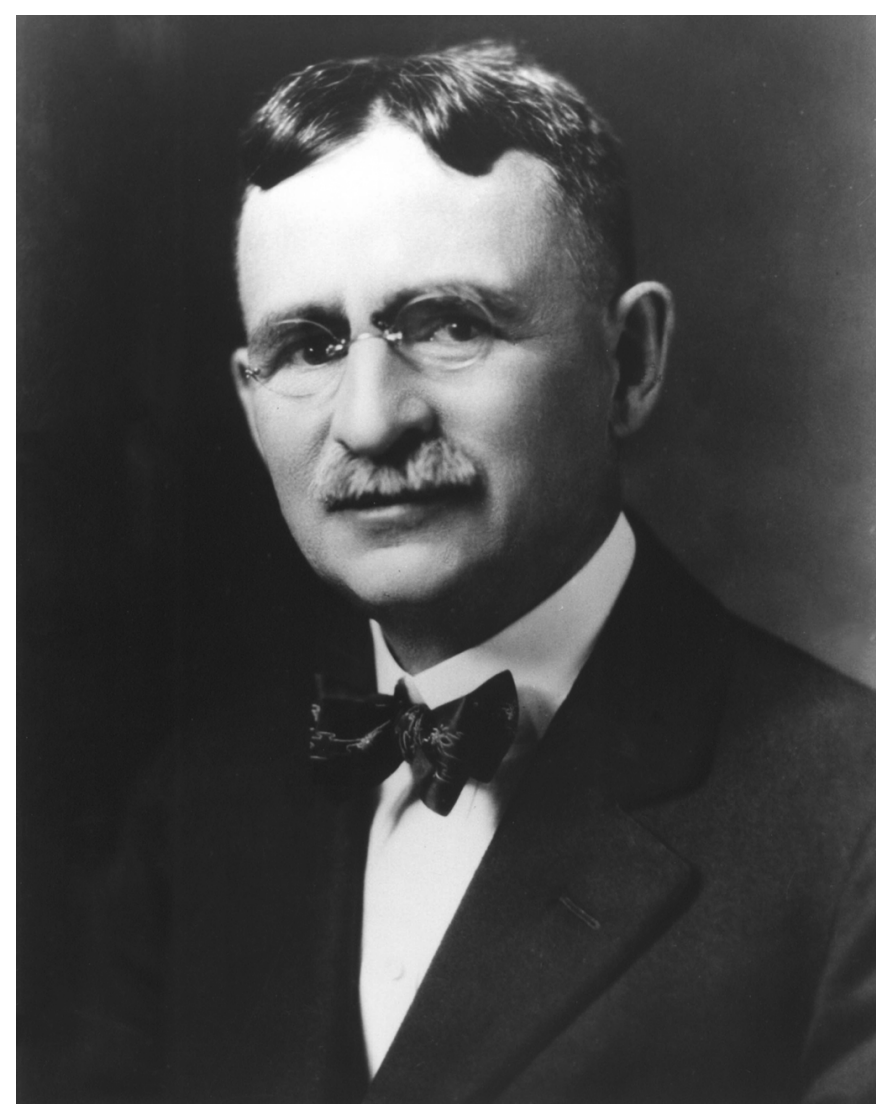

E. H. Moore, AMS President, 1901-1902.

McClintock felt caught in the middle. He agreed to speak, unofficially, on Newcomb's behalf at the dinner.

On February 24, 1899, Fiske was at the head of a table in the restaurant of the Grand Union Hotel. ${ }^{13}$ Bôcher and McClintock sat on each side of Fiske. About twenty AMS members were present. When the discussion began, a number of the younger men expressed support for a new research journal. Bôcher then asked McClintock to share his view. McClintock spoke from the heart, strongly opposing any action that would bring the Society into competition with Johns Hopkins and the journal that had meant so much to American mathematicians of his generation. The pleasant mood of the gathering abruptly ended. A confrontation loomed. Then Bôcher asked McClintock whether it would be improper for the Society to publish its Transactions. McClintock's response, that any Society was free to publish its Transactions, ended the impasse. A second barrier was overcome with a name for the new journal.

The special committee recommended to the Council that the Society begin publication of the Transactions, if possible, on January 1, 1900. The Council then appointed a committee consisting of Fiske (chair), Woodward, Bôcher, Pierpont, and Moore (i.e., the special committee with Woodward in place of Newcomb) to work on the financial arrangements.

\footnotetext{
${ }^{13}$ Our discussion of the dinner is drawn largely from Osgood's recollections on p. 58 in [2].
} 
Pierpont had already studied the matter. The approach became to have Society members solicit their universities to pledge $\$ 100$ a year for each of the next five years. Fortified with talking points from Pierpont, mathematicians became fundraisers.

The campaign was a success. Chicago, Columbia, Cornell, Northwestern, and Yale followed through with subventions for ten years. Other institutions provided support for shorter periods. The scheme supplied the Transactions with $\$ 8100$ over its first ten years. Sufficient funds were assured by its April 1899 meeting for the Society to authorize the journal. The Council appointed Moore, Ernest Brown, and Fiske as the first editorial board, which in turn elected Moore as the editor in chief.

Although a member of the Council, Moore did not travel to New York for the February or April meetings. He did take at least one trip during this period. On March 22 Moore visited Baltimore to explore an offer of a Johns Hopkins professorship. The recruitment began in January while Moore was considering whether to serve as an associate editor of the AJM. To a query from Newcomb, Moore responded that, while happy in Chicago, he was open to considering better circumstances. Over the following two months Newcomb and Gilman pressed for a campus visit while Moore sought details on remuneration and opportunities for building a department. Despite receiving neither, Moore was sufficiently interested to make the trip to Baltimore. Shortly after returning to Chicago, he declined the offer. If Moore had accepted, he likely would have become associated with the AJM, rather than the Transactions.

That Moore was the top choice of both Johns Hopkins and his AMS colleagues attested to his standing in the American mathematical community. A major international recognition came just after being named editor in chief. Moore was the only American among seven scientists awarded honorary degrees in a ceremony at Göttingen. The occasion was the unveiling of statues of Gauss and Wilhelm Weber. ${ }^{14}$

The timing of the 37-year-old Moore's acceptance of the demanding editorial position, with his career so rapidly ascending, was indicative of his commitment to elevating American scholarship. It should be said that he was not alone in giving of himself to advance the Transactions. Making the journal a reality had drawn together a group in common cause. Mathematicians outside the editorial board, such as Heinrich Maschke, White, Pierpont, Osgood, and Bôcher, were passionately devoted to bringing distinction to the journal.

A number of qualities made Moore an ideal editor in chief. His mathematical connoisseurship and his willing-

\footnotetext{
${ }^{14}$ Klein selected Moore while Hilbert chose Hadamard for the prestigious international awards. See P. 34 in October 1899 Bulletin and Henry Seely White Correspondence. Letter from Osgood, 10/30/1899. Columbia University Rare Book and Manuscript Library.
}

ness to work with authors to improve exposition ensured that the published papers were of high quality. But the Transactions was intended to showcase American mathematics, and Moore possessed a knack for subtle promotion that had already served the University of Chicago. The first issue of the Transactions included articles by White, Leonard Dickson (then at Texas), F. R. Moulton (Chicago), Maschke, Bôcher, Oskar Bolza (Chicago), G. A. Miller (Cornell), and Moore, all from American universities. As with the AJM, the Transactions carried papers by authors from European institutions, specifically Paul Gordan of Erlangen and Édouard Goursat of the University of Paris in the first issue. What was different with the Transactions was that, rather than being solicitations of the authors' choosing, the papers of Gordan and Goursat were inspired by earlier work of Americans. In planning the issue layout to lead off with White, Gordan, and then Goursat, Moore was deftly bringing attention to the acknowledgements by Gordan and Goursat that their work drew on papers by White and Osgood, respectively.

The American influence made a statement for the first issue, but was not a requirement for publication. The actual policy of the journal, in keeping with its transactions mission, was that all papers have been previously presented at a meeting of the Society, allowing in absentia contributions. Otherwise, foreign and domestic submissions were regarded on equal footing.

The creation of the Transactions coincided with the 1899 transfer of the Annals to Harvard. Bôcher, especially, worked diligently to make the Annals a valuable resource for faculty and graduate students. Nonetheless he operated with a clear understanding that the best material belonged in the Transactions. The timing of the Annals move to Harvard probably explains the absence of Bôcher from the original Transactions board. Osgood was abroad for the 1899-1900 academic year, residing with his family in Göttingen for most of the period. Throughout the year he followed the progress of both journals with great interest.

Osgood's own research began slowly in Europe. For several months he sought relief from insomnia and a neurological disorder. The symptoms abated, at least temporarily, toward the end of the fall. In the first days of 1900 Osgood's spirits were lifted by a letter from Newcomb with the passage

Sylvester's chair at the Johns Hopkins has never been filled. The university is now desirous of filling it, if only one of the leading men of the time can be found for the place. I have taken the liberty of suggesting you. Please tell me whether you are willing to allow the use of your name in this connection. ${ }^{15}$

\footnotetext{
${ }^{15}$ Henry Seely White Correspondence. In a 1/6/1900 letter from Osgood he quotes a 12/21/1899 letter from Newcomb to Osgood. Columbia Rare Book and Manuscript Library.
} 
Nine months after Moore turned Hopkins down, Newcomb was recruiting another mathematician from the younger generation. Osgood appeared more movable. At Harvard he was slated to serve three additional years at the rank of assistant professor before becoming eligible for promotion to professor. The most famous chair in the history of American mathematics would have seemed tempting. Yet Osgood was certain that, whatever the emoluments, they would not include the authority to hire "a body of men of my selection to man the department with and to guarantee keeping the department up to a first class standard."16 He saw better prospects with Bôcher at Harvard. Osgood declined further consideration.

Meanwhile, at Göttingen Osgood found mathematical stimulation in his interactions with Felix Klein, Arthur Schoenflies, and particularly David Hilbert. Osgood wrote to White with excitement over Hilbert's progress on the Dirichlet problem. His last extant letter to White is dated February 28, 1900, expressing the intention of auditing Hilbert's upcoming course. On June 2 Osgood boarded a ship for his return to New York. On the voyage he completed a manuscript that, soon after his return, was submitted to the Transactions. The paper, entitled "On the existence of the Green's function for the most general simply connected plane region," appeared in the journal's third (October) issue. Building on the work of Riemann, Poincaré, and others, Osgood resolved the crucial element of what is now known as the Riemann mapping theorem. ${ }^{17}$ Osgood's work on the Riemann mapping theorem placed him at the cutting edge of mathematical scholarship.

The younger American mathematicians were elated with the early volumes of the Transactions. Finally, the AMS provided an opportunity for meritorious papers to receive competent review and prompt publication. The editors sprinkled articles by distinguished Europeans, such as Hilbert and Jacques Hadamard, around the domestic material to confer an international prestige.

As with any American journal in 1900, the Transactions faced the challenges of traveling across the Atlantic Ocean and circulating through Europe. Consider the receptions, such as they were, to Osgood's article and to G. D. Birkhoff's seminal proof of Poincarés Last Geometric Problem a dozen years later. In the first edition of his classic text Complex Analysis [1], analytic function authority Lars Ahlfors states that many proofs have been given for the Riemann Mapping Theorem, without naming any names. For the second and third editions Ahlfors credits Paul Koebe with the first correct proof of the theorem, accompanied by the footnote: "A related theorem from which the mapping

\footnotetext{
$\overline{{ }^{16} \text { Henry Seely White Correspondence. Letter from Osgood, 2/28/1900s. }}$ Columbia Rare Book and Manuscript Library.

${ }^{17}$ For more on Osgood's work see [7] and the discussion by R. Narasimhan in [3].
}

theorem can be derived had been proved earlier by W. F. Osgood, but did not attract the attention it deserves."

Richard Courant was at Göttingen in 1913 when Birkhoff's result was published in the Transactions. Many years later, Courant recalled that the paper appeared in "some obscure American journal." Courant learned of the work from a review in Jahrbuch über die Fortschritte der Mathematik. Europeans were better able to access the proof when the Bulletin de la Société Mathématique de France took the unusual step of publishing a French translation of Birkhoff's Transactions paper. Unfortunately, the experiences of Osgood and Birkhoff demonstrate that the success in conveying the early twentieth century rise in American mathematics was mixed. As a consequence, the young Americans did not receive the respect abroad for their community that they desired and deserved.

While the Transactions became more a record than a showcase for American mathematics, its significance went well beyond its actual pages. The struggle to establish the journal drew Bôcher, Fiske, Moore, Osgood, Pierpont, White, and others of their generation together in solidarity. Pierpont's letters to White, after their crucial collaboration with Moore in Chicago, were written as if to a family member. Implementation of the Transactions was a team effort under the direction of Moore. The success was widely felt, empowering a generation in their thirties to take control and change the direction of the AMS. In 1900 Moore became the first 1860 s-born president of the Society. He was followed in two-year terms by Fiske, Osgood, White, and Bôcher. The leaders for the new century carried aspirations that had been shaped by their European experiences. American mathematics went on to flourish. In [3], I advance the view that by 1913 the significance of mathematical scholarship in the United States warranted comparable ranking with that of the leading European nations. The Transactions remains in operation today, the second sibling of a robust and evolving AMS periodical program in which the Journal of the AMS serves as the organization's flagship for papers of the highest quality. 


\section{HISTORY}

\section{References}

[1] Ahlfors L. Complex Analysis, McGraw-Hill, 1953, 1966, 1979. MR0054016

[2] Archibald R. A Semicentennial History of the American Mathematical Society 1888-1938, volume 1, American Mathematical Society, 1938. MR0959537

[3] Batterson S. American Mathematics 1890-1913 Catching up to Europe, Spectrum series of Mathematical Association of America, 2017. MR3675486

[4] Luck JJ. Ormond Stone-1847-1933, Bulletin American Mathematical Society, (39): 318-319. 1933. MR1562608

[5] Parshall K, Rowe D. The Emergence of the American Mathematical Research Community 1876-1900: J.J. Sylvester, Felix Klein, and E.H. Moore, American Mathematical Society, 1994. MR1290994

[6] Reid C. Courant in Göttingen and New York, Springer-Verlag, 1976. MR0532647

[7] Walsh J. History of the Riemann Mapping Theorem, American Mathematical Monthly,(80): 270-276, 1973. MR0323996

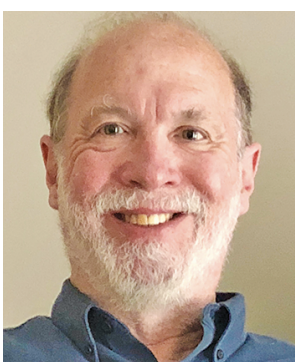

Steve Batterson

Credits

Photos of Thomas Fiske, Simon Newcomb, E. H. Moore, and Emory McClintock are courtesy of the AMS.

Photo of Pierpont, Osgood, and Bôcher is courtesy of Theodore Osgood with electronic enhancements by Beverly Ruedi.

Photo of Steve Batterson is by Ellen Neidle. 